\title{
Independent Risk Factors Predicting Gradual Onset Injury in 2824 Trail Running Race Entrants: SAFER XVIII Study
}

\author{
Carel T. Viljoen, $\mathrm{MSc}^{1,2,3}$; Nicola Sewry, $\mathrm{PhD}^{2,4}$; Martin P. Schwellnus, MD, $\mathrm{PhD}^{2,4,5}$; \\ Dina C. Janse van Rensburg, MD, $\mathrm{PhD}^{2,6}$; Sonja Swanevelder, $\mathrm{MSc}^{7}$; Esme Jordaan, $\mathrm{MSc}^{7,8}$ \\ ${ }^{1}$ Department of Physiotherapy, Faculty of Health Sciences, University of Pretoria, Pretoria, South Africa; ${ }^{2}$ Sport, Exercise Medicine and Lifestyle \\ Institute (SEMLI), University of Pretoria, Pretoria, South Africa; ${ }^{3}$ Amsterdam Collaboration for Health and Safety in Sports, Department of Public \\ and Occupational Health, Amsterdam Movement Sciences, Amsterdam University Medical Centres, VU University Medical Centre, Amsterdam, The \\ Netherlands; ${ }^{4}$ International Olympic Committee (IOC) Research Centre, Pretoria, South Africa; ${ }^{5}$ Sport and Exercise Medicine, Faculty of Health \\ Sciences, University of Cape Town, Cape Town, South Africa; ${ }^{6}$ Section Sports Medicine, Faculty of Health Sciences, University of Pretoria, \\ Pretoria, South Africa; ${ }^{7}$ Biostatistics Unit, South African Medical Research Council, Cape Town, South Africa; ${ }^{8}$ Statistics and Population Studies \\ Department, University of the Western Cape, Western Cape, South Africa
}

\begin{abstract}
Introduction-Trail running is characterized by elevation changes, with uneven and varying running surfaces. Risk factors that may predict gradual-onset running-related injuries (GORRIs) in short-distance trail running have not been explored. The objective was to determine risk factors that predict GORRIs in trail running race entrants who entered mass community-based trail running events.

Methods-In this descriptive cross-sectional study, data were collected prospectively from a prerace medical screening questionnaire over 4 trail run events held annually. Using a Poisson regression model, runner demographics, race distance, running training/racing variables, history of chronic diseases (number of chronic diseases reported as a cumulative "chronic disease composite score"), and allergies were investigated to determine factors predicting self-reported GORRI history in the previous 12 mo.

Results-This study included 2824 race entrants (80\% of entrants). The retrospective annual incidence for GORRIs was $13 \%$. Independent risk factors predicting GORRIs were longer race distance $(P<0.0001)$, increasing chronic disease composite score $(P=0.0012)$, and a history of allergies $(P=0.0056)$. The lower limb $(94 \%)$ was the main anatomic region of GORRIs, and soft tissue injuries accounted for most (83\%) GORRIs. Common specific GORRIs were iliotibial band syndrome (22\%), Achilles tendon injury (10\%), and hamstring injury (9\%).

Conclusions-Independent risk factors predicting GORRIs among trail running entrants included longer race distance, a higher chronic disease composite score, and a history of allergies. This study has highlighted trail running race entrants at risk for sustaining GORRIs who could be targeted for future injury prevention interventions.
\end{abstract}

Keywords: chronic disease, running related injuries, incidence, epidemiology, off-road running, prerace medical screening

\section{Introduction}

Physical activity is associated with a reduced risk for developing chronic disease and premature all-cause

Corresponding author: Carel T. Viljoen, MSc, Department of Physiotherapy, Faculty of Health Sciences, University of Pretoria, Prinshof Campus, Gezina, Pretoria 0007, South Africa; e-mail: carel.viljoen@up.ac.za.

Submitted for publication November 2020.

Accepted for publication April 2021. mortality. ${ }^{1}$ Evidence further suggests that participating in outdoor physical activity improves mental well-being. ${ }^{2}$ Trail running involves running on off-road terrains in outdoor environments and is characterized by large elevation changes. ${ }^{3}$ Although running has numerous proven physical and mental health benefits, it is still associated with a high risk for injury. ${ }^{4}$

The most common injuries described in the running literature involve gradual-onset running-related injuries (GORRIs) $^{4,5}$ as a result of low kinetic energy transfer over 
time causing tissue damage. ${ }^{6}$ Most studies only focus on marathon and ultramarathon running distances, ${ }^{7-14}$ with limited information on GORRIs among trail runners participating in shorter-distance trail run events.

In one study among ultradistance trail runners, injury risk factors among elite runners included more experience in running and physical labor occupations. However, the authors did not investigate the medical history of participants. ${ }^{13}$ The prevalence of certain chronic diseases among endurance runners is up to $13 \%,{ }^{15}$ and chronic diseases are also associated with an increased risk for gradual-onset injuries. ${ }^{16-20}$ Additionally, some medications used in the treatment of chronic diseases are associated with an increased risk for injury. ${ }^{21-27}$ The relationship between chronic diseases and risk of GORRIs has not been explored in trail runners.

The importance of investigating injury profiles and determining associated injury risk factors for GORRIs in this population is emphasized by the challenges faced during medical coverage at some trail running events. ${ }^{28}$ These events can span large geographical regions in remote settings where medical staff and runners are exposed to environmental hazards that include extreme weather, water crossings, insect-borne infections, and wildlife. $^{28,29}$ In these settings, injured runners often receive delayed medical care owing to the logistical challenges of providing emergency medical care in remote regions. ${ }^{28,29} \mathrm{~A}$ history of injury is a known injury risk factor among runners ${ }^{30,31}$; therefore, an attempt should be made to prevent injury in the training period before race participation. For specific injury prevention strategies for short-distance trail runners in the training period before race participation, we need an improved understanding of the injury profiles and associated injury risk factors for GORRIs in this population.

The main aim of this study was to determine risk factors that predict a history of GORRIs in trail running race entrants who entered mass community-based trail running events. A secondary aim was to report the epidemiology and clinical characteristics of self-reported GORRIs among trail running race entrants.

\section{Methods}

\section{STUDY DESIGN}

This is a descriptive cross-sectional analysis of data collected prospectively at 4 annual trail running events.

\section{PARTICIPANTS AND DATA COLLECTION}

The research ethics committee of the University of Cape Town (REC 009/2011 and REC 030/2013) approved the protocol, and the research ethics committee of the University of Pretoria (REC 433/2015) approved the ongoing data collection and subsequent analysis of the data.

This study forms part of the strategies to reduce adverse medical events for the exerciser (SAFER) studies-SAFER XVIII. Participants in this study were race entrants from the Two Oceans trail runs, a mass community-based trail running event in South Africa that is composed of a $10-\mathrm{km}$ and a $22-\mathrm{km}$ race. No qualification was required for either of the events. Entrants were defined as any runner registering for the races (registration typically opens 3-5 mo before the races) held annually over 4 y (2012-2015).

\section{ONLINE PRERACE MEDICAL SCREENING}

In this 4-y study period, a compulsory prerace medical screening questionnaire was implemented for all race entrants. The prerace medical screening questionnaire was based on the European Association for Cardiovascular Prevention and Rehabilitation recommendations ${ }^{32}$ and consisted of the following main categories: history of cardiovascular disease (CVD), symptoms of CVD, risk factors for CVD, other chronic diseases, general prescription medication use, medication use during racing, injury, and a history of collapse during racing. The full details of this online medical screening and implementation thereof have been described in previous studies. $^{15,33}$ Entrants completing the screening were given the opportunity to consent to their data being used for research purposes.

In the prerace medical screening, entrants were asked the following specific question related to gradual-onset injuries: "Do you or did you suffer from any symptoms of a chronic (no accident) running injury (muscles, tendons, bones, ligaments or joints) in the past 12 months or currently?" We defined these injuries as GORRIs, as recommended by the 2020 International Olympic Committee consensus statement. ${ }^{6}$ For inclusion, an injury was defined as "An injury that is/was severe enough to interfere with running or require treatment, eg, use medication or require you to seek medical advice from a health professional." If the response to the previous question was "yes," entrants were required to complete additional questions related to the gradual-onset running injury, including where it is a past or current injury, anatomic region, body area, type of anatomic structure, severity, and whether the injury was one of the more commonly known GORRIs.

\section{PRIMARY OUTCOME}

The primary outcome of this study was a history of GORRIs in the past 12 mo among trail running race 
entrants. The following 3 categories of independent variables of interest as factors predicting GORRIs were explored: 1) demographics (sex and age groups) and race distance; 2) running training/racing variables (years as a recreational runner, average weekly training/running frequency in the last $12 \mathrm{mo}$, average weekly training/ running distance in the past $12 \mathrm{mo}$, average training speed, race vs average training speed ratio); and 3) history of chronic disease (any risk factors for CVD, history of existing CVD, symptoms of CVD, endocrine disease, respiratory disease, gastrointestinal disease, nervous system/psychiatric disease, kidney/bladder disease, hematological/immune system disease, and cancer) and any allergies. We calculated a further variable, a chronic disease composite score (out of 10), which is a continuous variable of the sum of an individual's answer to 10 questions related to the aforementioned history of chronic disease.

In reporting on the outcomes in this manuscript, we use the terminology "prediction" instead of "association," based on recently published guidelines regarding clear goal setting in sports injury research. ${ }^{34}$ In addition, we report the retrospective annual incidence (percentage of runners: 95\% CI) and frequency of injury characteristics (percentage of injuries) for anatomic region, body area, tissue type, and common specific GORRIs. Injury severity was recorded as frequency (percent) of less severe (Grade I-only experience symptoms after exercise; and Grade II-experience symptoms during exercise but they do not interfere with exercise) and more severe (Grade III-experience symptoms during exercise that may interfere with training/competition; and Grade IV-may not be able to train/compete due to pain) injuries. ${ }^{35}$ More severe injuries were classified as those that interfered with the runner's ability to continue with training or racing.

\section{STATISTICAL ANALYSIS}

All race entrants' data were entered into Microsoft Excel and then transferred into SPSS statistical software (version 25) and SAS (V.9.4) statistical analysis system. The binary-scaled dependent variable in the model was the response to the question related to GORRI. Entrants were coded as having a GORRI if they reported 1) a GORRI in the past 12 mo or 2) a current GORRI. Entrants could report more than 1 injury. Frequency analysis was performed for the descriptive data (percentage of all entrants; 95\% CIs). For the risk factors, 2 groups were used (injured group, $n=338$; control group, $n=2486$ ), a Poisson distribution with a log link function was used, and the $P$-values for a Type 3 GEE analysis were reported. All possible factors were first explored in a
Table 1. Characteristics of all trail run race entrants and study participants

\begin{tabular}{llll}
\hline Characteristics & $\begin{array}{c}\text { All trail run } \\
\text { entrants } \\
(n=3547)\end{array}$ & $\begin{array}{c}\text { Study } \\
\text { participants } \\
(n=2824)\end{array}$ & \\
\cline { 2 - 2 }$\%^{a}(n)$ & & $\%^{a}(n)$ & \\
\cline { 1 - 2 } Sex & & & \\
$\quad$ Male & $57(2003)$ & $57(1597)$ & 0.9485 \\
$\quad$ Female & $44(1544)$ & $43(1227)$ & \\
Age groups (y) & & & \\
$\leq 30$ & $30(1073)$ & $30(857)$ & 0.9124 \\
$31-40$ & $37(1312)$ & $36(1022)$ & \\
$41-50$ & $23(816)$ & $24(666)$ & \\
$>50$ & $10(346)$ & $10(279)$ & \\
Race distance $(\mathrm{km})$ & & & \\
10 & $41(1463)$ & $40(1131)$ & 0.3342 \\
22 & $59(2084)$ & $60(1693)$ & \\
\hline
\end{tabular}

${ }^{\mathrm{a}}$ Percentage of the total.

${ }^{\mathrm{b} P}$ value-all trail run entrants vs entrants consenting as study participants.

univariate analysis. Using highly significant factors $(P<0.001$, owing to the small sample size $)$ from the univariate model, a multiple regression model was performed. Prevalence ratios (PR; 95\% CIs) were reported, and a final significance level of $<0.05$ was accepted.

\section{Results}

Over the 4 annual events, 3547 runners entered and 2824 entrants (80\%) gave consent for their data to be analyzed (10 km [n=1131] and $22 \mathrm{~km}[\mathrm{n}=1693])$. There were no significant differences between entrants who consented to study participation and all race entrants by sex, age group, or race distance (Table 1).

\section{ANNUAL INCIDENCE OF GORRIS}

In the previous $12 \mathrm{mo}, 338$ trail running race entrants reported a total of 349 GORRIs. Eleven (3\%) of the 338 participants reported a second injury (total injuries, $\mathrm{n}=349)$ and $82(24 \%)$ of the 338 participants had a "current" injury at the time of completing the prerace screening questionnaire at race registration. The retrospective annual incidence of injuries in this study population was $13 \%$ (95\% CI: 11-14).

\section{CHARACTERISTICS OF GORRIS AMONG TRAIL RUNNING RACE ENTRANTS}

The main anatomic region affected by GORRIs was the lower limb (94\%: $n=328)$, followed by the trunk (5\%: $\mathrm{n}=16)$ and the upper limb (1\%: $\mathrm{n}=2)$. The most common 
Table 2. Anatomic region and specific body area of gradualonset running-related injuries among trail running race entrants $(n=349)$

\begin{tabular}{llc}
\hline Anatomic region & Body area & $\%(n)$ \\
\hline Head and neck & Head & $0(1)$ \\
Upper limb & Shoulder & $0(1)$ \\
& Wrist & $0(1)$ \\
Trunk & & $5(16)$ \\
Lower limb & Hip/Groin/Pelvis & $5(18)$ \\
& Thigh & $11(38)$ \\
& Knee & $35(123)$ \\
& Achilles tendon & $11(37)$ \\
& Shin/Lower leg/Calf & $16(55)$ \\
& Ankle & $6(21)$ \\
& Foot & $10(36)$ \\
Unspecified & & $1(2)$ \\
\hline Total & & $100(349)$ \\
\hline
\end{tabular}

body areas affected by GORRIs were the knee (35\%: $\mathrm{n}=123)$, followed by the shin/lower leg/calf $(16 \%: \mathrm{n}=55)$ and the thigh $(11 \%: \mathrm{n}=38)$ (Table 2).

The most common specific GORRI was iliotibial band syndrome (ITBS) (22\%: $\mathrm{n}=78$ ), followed by Achilles tendon injury (10\%: $n=35)$, hamstring injury $(9 \%: n=30)$, calf muscle injury $(7 \%: \mathrm{n}=23)$, and foot/heel pain $(5 \%$ : $\mathrm{n}=19)$ (Table 3).

The frequency of Grade IV injuries (not able to train or compete due to injury) was $18 \%(\mathrm{n}=63)$. The frequency of Grade III injuries was 33\% ( $\mathrm{n}=114)$, followed by Grade II $(26 \%$ : $n=90)$ and Grade I $(23 \%$ : $n=79)$. Slightly more severe GORRIs were reported among $51 \%$ $(\mathrm{n}=177)$ compared to less severe injuries among $48 \%$ $(n=169)$.

\section{RISK FACTORS PREDICTING A HISTORY OF GRADUAL-ONSET INJURIES IN TRAIL RUNNING RACE ENTRANTS (UNIVARIATE ANALYSIS)}

Runner demographics (sex, age group) and race distance

The overall prevalence of GORRIs $(\mathrm{n}=338)$ among trail running race entrants was $12 \%$ (95\% CI: $11-14)$. The prevalence of GORRIs was not significantly different between males and females ( $\mathrm{PR}=1.0, P=0.7722)$ or across age groups $(P=0.1246)$. There was a higher prevalence of GORRIs among trail running race entrants participating in the longer-distance race $(\mathrm{PR}=1.8$, $P<0.0001)$ (Table 4).

\section{RUNNING TRAINING/RACING HISTORY}

The number of years of recreational running $(\mathrm{PR}=1.1$ per 5-unit increase; $P=0.0014$ ) and an increased average weekly training/running distance in the last 12 mo
( $\mathrm{PR}=1.0$ per 5-unit increase; $P=0.0061)$ were associated with an increased PR for GORRIs (Table 5).

\section{HISTORY OF CHRONIC DISEASE AND ALLERGIES}

The results of trail running race entrants with a GORRI by history of chronic disease and allergies is shown in Table 6.

A higher chronic disease composite score was associated with a higher prevalence of GORRIs among trail running race entrants $(\mathrm{PR}=1.7 ; P=0.0004)$ in a "dose-dependent" fashion (Figure 1). For every 2 additional chronic diseases, the prevalence of GORRIs increased 1.7 times. Notably, the confidence intervals widened as the score increased, owing to the number of entrants with higher composite scores decreasing. A history of any allergies $(\mathrm{PR}=1.7, P=0.0008)$ was associated with a higher PR for GORRIs among trail running race entrants.

\section{INDEPENDENT RISK FACTORS PREDICTING A HISTORY OF GORRIS IN TRAIL RUNNING RACE ENTRANTS (MULTIPLE REGRESSION ANALYSIS)}

Independent risk factors predicting a history of GORRIs in trail running entrants were longer race distance $(\mathrm{PR}=1.9, P<0.0001)$, a higher chronic disease composite score $(\mathrm{PR}=1.6, P=0.0012)$, and a history of any allergies $(\mathrm{PR}=1.6, P=0.0056)$ (Table 7).

\section{Discussion}

In our study, runners entering for the longer trail run had a higher prevalence of self-reported GORRIs. Runners

Table 3. Frequency of common specific gradual-onset runningrelated injuries (12 mo prior to race entry) among trail running race entrants $(\mathrm{n}=349)$

\begin{tabular}{lc}
\hline $\begin{array}{l}\text { Common specific gradual-onset } \\
\text { running-related injuries }\end{array}$ & $\%(n)$ \\
\hline Knee-iliotibial band syndrome & $22(78)$ \\
Achilles tendon injury & $10(35)$ \\
Hamstring injury & $9(30)$ \\
Calf muscle injury & $7(23)$ \\
Foot or heel pain & $5(19)$ \\
Anterior knee pain/Patellofemoral pain & $5(16)$ \\
Lower back pain & $4(15)$ \\
Plantar fasciitis & $4(14)$ \\
Hip muscle injury & $3(12)$ \\
(including gluteus/buttock muscles) & \\
Shin splints (muscle/tendon) & $3(10)$ \\
Shin splints (bone) & $2(8)$ \\
Quadriceps muscle injury & $1(3)$ \\
Lower leg compartment syndrome & $1(2)$ \\
Other & $24(84)$ \\
\hline Total & $100(349)$ \\
\hline
\end{tabular}


Table 4. Number, prevalence, and PR of trail running race entrants with a history of GORRI by race distance, sex, and age group

\begin{tabular}{|c|c|c|c|c|c|}
\hline \multirow[t]{2}{*}{ Characteristics } & \multirow{2}{*}{$\begin{array}{l}\text { Study participants }(n=2824) \\
n\end{array}$} & \multicolumn{2}{|c|}{ Study participants with a GORRI $(n=338)$} & \multirow[t]{3}{*}{$P R(95 \% C I)$} & \multirow[t]{3}{*}{$\mathrm{P}$ value } \\
\hline & & $n$ & Prevalence (\%; (95\% CI) & & \\
\hline Overall & 2824 & 338 & $13(11-14)$ & & \\
\hline \multicolumn{6}{|c|}{ Runner demographics } \\
\hline \multicolumn{6}{|l|}{ Sex } \\
\hline Male & 1568 & 184 & $12(10-14)$ & $1.0(0.8-1.3)$ & 0.7722 \\
\hline Female & 1210 & 154 & $12(11-14)$ & & \\
\hline \multicolumn{6}{|l|}{ Age groups $(y)$} \\
\hline$\leq 30$ & 840 & 86 & $10(8-13)$ & & 0.1246 \\
\hline $31-40$ & 1002 & 128 & $13(11-15)$ & $1.3(1.0-1.7)$ & \\
\hline $41-50$ & 663 & 92 & $14(11-17)$ & $1.4(1.0-1.8)$ & \\
\hline$>50$ & 273 & 32 & $11(8-16)$ & $1.1(0.7-1.6)$ & \\
\hline \multicolumn{6}{|c|}{ Race distance $(\mathrm{km})$} \\
\hline 10 & 1113 & 93 & $8(7-10)$ & $1.8(1.4-2.3)$ & $<0.0001^{a}$ \\
\hline 22 & 1665 & 245 & $15(13-17)$ & & \\
\hline
\end{tabular}

GORRI, gradual-onset running-related injury; PR, prevalence ratio.

Missing data in 46 entrants.

${ }^{\text {a }}$ Statistically significant.

entering longer-distance races are usually more experienced and train at higher weekly running distances in comparison to entrants of shorter-distance races. Among Greek trail runners, increased running experience was associated with a higher risk of injury. ${ }^{13}$ We found similar results in our univariate analysis, indicating that increased years of running were associated with a higher PR of a GORRI. Our univariate analysis also indicated that an increased average weekly running distance was associated with a higher prevalence of a GORRI. Future

Table 5. Prevalence and PR of trail running race entrants with a GORRI by training/racing history (unadjusted)

\begin{tabular}{|c|c|c|c|c|}
\hline $\begin{array}{l}\text { Running training/ } \\
\text { racing history }\end{array}$ & $\begin{array}{l}\text { Points in the continuous } \\
\text { variable }^{a}\end{array}$ & $\begin{array}{l}\text { Trail run race entrants with } \\
\text { a GORRI }(n=338) \text { : } \\
\text { prevalence }(\% ; 95 \% \text { CI) }\end{array}$ & $P R(95 \% C I)$ & $\mathrm{P}$ value \\
\hline $\begin{array}{l}\text { Time as a recreational } \\
\text { runner }(y)\end{array}$ & $\begin{array}{l}3 \\
6 \\
13\end{array}$ & $\begin{array}{l}11(9-12) \\
11(10-13) \\
13(12-14)\end{array}$ & $\begin{array}{l}\text { 5-unit increase } \\
1.1(1.0-1.2)\end{array}$ & $0.0014^{a}$ \\
\hline $\begin{array}{l}\text { Average weekly } \\
\text { training/ running } \\
\text { frequency in the last } \\
12 \mathrm{mo}\left(\mathrm{times}^{-} \cdot \mathrm{wk}^{-1}\right)\end{array}$ & $\begin{array}{l}2 \\
3 \\
4\end{array}$ & $\begin{array}{l}11(9-13) \\
12(11-13) \\
13(11-14)\end{array}$ & $\begin{array}{l}\text { 2-unit increase } \\
1.1(1.0-1.3)\end{array}$ & 0.0610 \\
\hline $\begin{array}{l}\text { Average weekly } \\
\text { training/running } \\
\text { distance in the past } \\
12 \text { mo }(\mathrm{km})\end{array}$ & $\begin{array}{l}15 \\
25 \\
40\end{array}$ & $\begin{array}{l}11(10-12) \\
12(11-13) \\
13(12-15)\end{array}$ & $\begin{array}{l}\text { 5-unit increase } \\
1.0(1.0-1.1)\end{array}$ & $0.0061^{a}$ \\
\hline $\begin{array}{l}\text { Average training speed } \\
\left(\mathrm{km} \cdot \mathrm{h}^{-1}\right)\end{array}$ & $\begin{array}{l}9 \\
11 \\
13\end{array}$ & $\begin{array}{l}12(10-13) \\
12(11-14) \\
13(11-14)\end{array}$ & $\begin{array}{l}\text { 1-unit increase } \\
1.0(1.0-1.1)\end{array}$ & 0.5046 \\
\hline $\begin{array}{l}\text { Race vs training speed } \\
\text { ratio }\left(\mathrm{RS} / \mathrm{TS}^{b}\right)\end{array}$ & $\begin{array}{l}0.5 \\
1.0 \\
1.5\end{array}$ & $\begin{aligned} 14 & (12-17) \\
11 & (9-13) \\
8 & (5-13)\end{aligned}$ & $\begin{array}{l}0.5 \text {-unit increase } \\
1.0(0.9-1.1)\end{array}$ & 0.0590 \\
\hline
\end{tabular}

GORRI, gradual-onset running-related injury; PR, prevalence ratio.

${ }^{\text {a }}$ Statistically significant.

${ }^{\mathrm{b}}$ Race speed $\left(\mathrm{km} \cdot \mathrm{h}^{-1}\right)$ vs training speed $\left(\mathrm{km} \cdot \mathrm{h}^{-1}\right)$ ratio = race speed/training speed; a value $>1$ is a faster average race speed compared to average training speed, and a value $<1$ is a slower average race speed compared to average training speed. 
Table 6. Number, prevalence, and PR of trail running race entrants with a GORRI by history of chronic disease and allergies (unadjusted)

\begin{tabular}{|c|c|c|c|c|c|}
\hline \multirow[t]{2}{*}{ Characteristics } & \multirow{2}{*}{$\begin{array}{l}\text { Study participants } \\
(n=2824) \\
n\end{array}$} & \multicolumn{2}{|c|}{ Race entrants with a GORRI $(n=338)$} & \multirow[t]{2}{*}{$P R(95 \% C I)$} & \multirow[t]{2}{*}{$\mathrm{P}$ value } \\
\hline & & $n$ & Prevalence (\%; $95 \%$ CI) & & \\
\hline \multicolumn{6}{|c|}{$\begin{array}{l}\text { History of chronic } \\
\text { disease } \\
\text { Chronic disease } \\
\text { composite score }(0-10)^{a}\end{array}$} \\
\hline 0 & - & - & $11(10-12)$ & 2-unit increase & $0.0004^{b}$ \\
\hline 2 & - & - & $19(15-23)$ & $1.7(1.4-2.2)$ & \\
\hline 4 & - & - & $32(21-49)$ & & \\
\hline \multicolumn{6}{|c|}{ History of allergies } \\
\hline Any allergies & & & & & \\
\hline Yes & 322 & 65 & $19(15-24)$ & $1.7(1.3-2.2)$ & $0.0008^{b}$ \\
\hline No & 2455 & 273 & $11(10-13)$ & & \\
\hline Missing & 47 & 0 & & & \\
\hline
\end{tabular}

GORRI, gradual-onset running-related injury; PR, prevalence ratio.

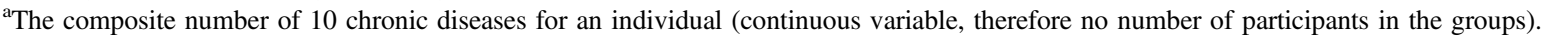

${ }^{\mathrm{b}}$ Statistically significant.

studies using larger sample sizes may identify running experience and weekly running distance as independent risk factors predicting a history of GORRIs.

We showed that a higher chronic disease composite score predicted a history of GORRIs. Specifically, for every 2 additional chronic diseases present, the prevalence of GORRIs increased 1.6 times in a "dose-dependent" fashion. This is an intriguing finding. The prevalence of chronic disease among endurance runners has been reported at 2 to $13 \%$, and $16 \%$ of runners have at least 1 risk factor for CVD. ${ }^{15}$ Studies confirm that a variety of chronic diseases, which affect various organ systems, are associated with an increased risk for gradual-

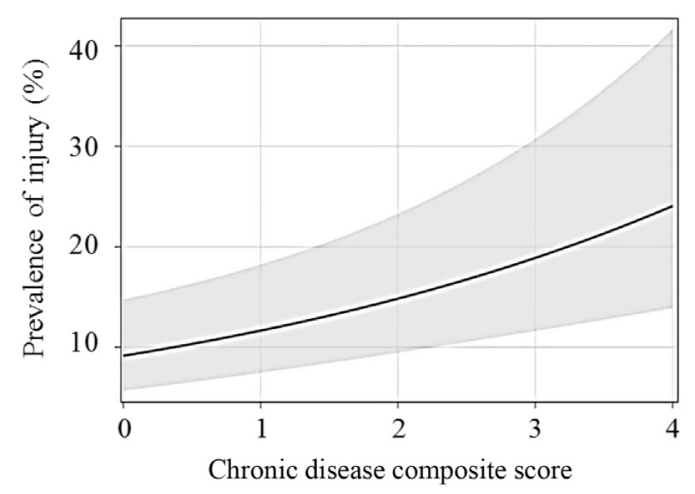

Figure 1. The relationship between the prevalence of gradual-onset running-related injuries and the number of chronic diseases (chronic disease composite score) (shaded area is $95 \% \mathrm{CI}$ ). Wide confidence intervals are indicative of the small sample size at that score. onset injuries. ${ }^{16-20}$ For example, diabetes mellitus, hypercholesteremia, and obesity are associated with a higher risk of tendinopathy, ${ }^{16-18}$ and chronic obstructive pulmonary disease is associated with an increased risk for bone stress injuries. ${ }^{19,20}$

Another consideration is that the medications used in the treatment of chronic diseases may be associated with an increased risk for injury. ${ }^{21-27}$ There are reports that drug-induced tendinopathy is associated with the use of fluoroquinolones, ${ }^{24}$ statins, ${ }^{22,25}$ corticosteroids, ${ }^{21}$ aromatase inhibitors, ${ }^{27}$ and isotretinoin. ${ }^{23} \mathrm{~A}$ higher risk for tendon ruptures ${ }^{21}$ and osteoporosis ${ }^{26}$ has been reported with the use of corticosteroids, and isotretinoin use increased the risk for developing enthesopathy. ${ }^{23}$ The relationship between the medication dosage and adverse effects is not well quantified in the use of corticosteroids, ${ }^{26}$ but the adverse effects of statins appear to be dose-dependent. Finally, certain medication interactions are associated with increased tendon toxicity, ${ }^{36}$ and combinations of medications are a further risk factor for developing toxic tendinopathy. ${ }^{37}$

The cross-sectional nature of our study limits our ability to establish a cause-effect relationship between the chronic disease composite score and injury risk. These findings do suggest that not only the presence of chronic disease but also the choice of medication used in treatment, medication dosage, and medication interactions need to be explored as risk factors for GORRIs in future studies.

We also showed that a history of allergies predicted a history of GORRIs. Trail runners participate in various 
Table 7. Independent risk factors that predict a history of GORRIs in the past 12 mo (multiple regression analysis)

\begin{tabular}{lcc}
\hline & $\begin{array}{c}\text { Runners with a GORRI } \\
\%(95 \% \text { CI })\end{array}$ & PR (95\% CI) \\
\hline Race distance $(\mathrm{km})$ & $9(7-11)$ & $1.9(1.5-2.4)$ \\
10 & $17(15-20)$ & \\
22 & & \\
History of chronic disease & $12(10-14)$ & 2-unit increase: \\
$\quad$ Chronic disease composite score ${ }^{b}$ & $19(15-23)$ & $1.6(1.3-2.1)$ \\
0 & $30(20-46)$ & \\
2 & & $1.6(1.2-2.0)$ \\
4 & $18(14-22)$ & $0.0012^{a}$ \\
History of allergies & $11(10-13)$ & $0.0056^{a}$ \\
Any allergies & & \\
Yes & & \\
No & & \\
\hline
\end{tabular}

Adjusted for age and sex.

GORRI, gradual-onset running-related injury; PR, prevalence ratio.

${ }^{\text {a }}$ Statistically significant.

${ }^{\mathrm{b}}$ The composite number of 10 chronic diseases for an individual (continuous variable).

outdoor settings where they are exposed to a variety of potential allergens. Trail running is an endurance sport, and it is well established that a history of allergies is common in endurance athletes. ${ }^{15,38}$ We can only speculate on the possible reasons for the association between allergies and GORRI. Again, both the allergy itself and the medication used to treat it may be mechanisms responsible for the increased risk of injury. Antihistamines are commonly used to treat allergies but have side effects such as fatigue and drowsiness. ${ }^{39}$ If this medication is used during training and racing, acute fatigue can alter lower extremity muscle strength, postural control, and ankle joint position sense, which may increase injury risk. ${ }^{40}$ Future research should explore the relationship between allergies, the medication used to treat allergies, and GORRIs.

This is the only study to report the annual incidence (13\%) of GORRIs among short-distance trail running race entrants; therefore, we could not compare our results to any current literature. Our results show that the lower limb (94\%) is the most commonly injured anatomic region, and this finding is similar to that previously reported among longer-distance trail runners. ${ }^{8,9,11,13,14,41}$ In our study, the knee was the most common body area for GORRIs (35\%), at a rate that is much higher compared to Dutch trail runners (18\%). ${ }^{41}$ In downhill running, the knee is exposed to increased flexion angles during load absorption and redistribution, and this may contribute to the higher prevalence of knee injuries. ${ }^{42}$ The lower frequency of knee injuries reported among Dutch trail runners ${ }^{41}$ may be related to a difference in the trail running landscape in the Netherlands, with minimal elevation changes.
Our results indicated that soft tissue accounted for $82 \%$ of all injured tissue types. The specific tissues involved were muscle (33\%), followed by tendon (30\%) and ligament (18\%), and these findings are similar to those reported in Dutch trail runners (muscle $=28 \%$, tendon $=24 \%$, ligament $=7 \%){ }^{41}$ In ultradistance trail runners, similar injured tissue types were found (tendon: $36 \%$; ligament: 43\%; and muscle: $21 \%) .{ }^{11}$ However, we note that in the Italian trail running study, acute injuries were included, specifically a high number of ankle sprains. Therefore, we cannot strictly compare our data to that study. ${ }^{11}$

Finally, we show that $51 \%$ of GORRIs are severe enough to interfere with training or competition (Grade III and IV). Although Grade IV injuries were the least frequently reported (18\%), they are of concern if a trail runner cannot continue with running owing to pain, especially during training/racing in remote regions where medical evacuation is challenging. ${ }^{28}$ We cannot compare this finding to other studies because there is substantial variation in the definition of injury severity in the trail running literature, ${ }^{8,41}$ which restricts our ability to compare results.

\section{LIMITATIONS}

This study has several limitations. We cannot determine a cause-effect relationship between any of the identified risk factors because of the cross-sectional nature of the study. All injury and training data are self-reported and could have been affected by recall bias. Owing to recall bias, we could not accurately determine the study participants' actual running exposure on trails. The diagnosis of injuries could not be verified. Lastly, we acknowledge 
that many other factors (eg, elevation change, running surface, individuals' level of conditioning, intrinsic lower limb biomechanics, footwear) may also be associated with the risk for developing GORRIs, but these could not be explored in our study. Future studies are needed to explore the causal relationship between the risk factors and GORRIs among short-distance trail running race entrants.

\section{Conclusions}

Independent risk factors that predict a history of GORRIs among short-distance trail running entrants include longer race distance, a higher chronic disease composite score, and history of any allergies. Specifically, for every 2 additional chronic diseases present, the prevalence of GORRIs increased by 1.6 times in a "dose-dependent" fashion. Our results highlight trail running race entrants at risk for sustaining GORRIs who could be targeted for future injury prevention interventions.

Author Contributions: Study concept (CTV, NS, MS); study planning (CTV, NS, MS, CJvR, EJ); data analysis/interpretation (CTV, NS, MS, CJvR, EJ); writing of the manuscript, (CTV); manuscript editing (CTV, NS, MS, CJvR, SS, EJ); responsible for the overall content as guarantor (MS); statistical analysis (CJvR, EJ). All authors approved the final version of this manuscript.

Financial/Material Support: None.

Disclosures: None.

\section{References}

1. Lee D-C, Brellenthin AG, Thompson PD, Sui X, Lee IM, Lavie CJ. Running as a key lifestyle medicine for longevity. Prog Cardiovasc Dis. 2017;60(1):45-55.

2. Thompson Coon J, Boddy K, Stein K, Whear R, Barton J, Depledge $\mathrm{MH}$. Does participating in physical activity in outdoor natural environments have a greater effect on physical and mental wellbeing than physical activity indoors? A systematic review. Environ Sci Technol. 2011;45(5):1761-72.

3. Scheer V, Basset P, Giovanelli N, Vernillo G, Millet GP, Costa RJS. Defining off-road running: a position statement from the ultra sports science foundation. Int J Sports Med. 2020;41(5):275-84.

4. Messier SP, Martin DF, Mihalko SL, Ip E, DeVita P, Cannon DW, et al, A 2-year prospective cohort study of overuse running injuries: the runners and injury longitudinal study (TRAILS). Am J Sports Med. 2018;46(9):2211-21.

5. Lopes AD, Hespanhol Junior LC, Yeung SS, Costa LO. What are the main running-related musculoskeletal injuries? A systematic review. Sports Med. 2012;42(10):891-905.

6. Bahr R, Clarsen B, Derman W, Dvorak J, Emery CA, Finch $\mathrm{CF}$, et al. International Olympic Committee consensus statement: methods for recording and reporting of epidemiological data on injury and illness in sport 2020 (including STROBE extension for sport injury and illness surveillance (STROBE-SIIS)). $\mathrm{Br} \quad J$ Sports Med. 2020;54(7):372-89.

7. Graham SM, McKinley M, Chris CC, Westbury T, Baker JS, Kilgore L, et al. Injury occurrence and mood states during a desert ultramarathon. Clin J Sport Med. 2012;22(6):462-6.

8. Krabak BJ, Waite B, Schiff MA. Study of injury and illness rates in multiday ultramarathon runners. Med Sci in Sports Exerc. 2011;43(12):2314-20.

9. Scheer BV, Murray A. Al Andalus Ultra Trail: an observation of medical interventions during a 219-km, 5-day ultramarathon stage race. Clin $J$ Sport Med. 2011;21(5):444-6.

10. McGowan V, Hoffman MD. Characterization of medical care at the 161-km Western States Endurance Run. Wilderness Environ Med. 2015;26(1):29-35.

11. Vernillo G, Savoldelli A, La Torre A, Skafidas S, Bortolan L, Schena F. Injury and illness rates during ultratrail running. Int J Sports Med. 2016;37(7):565-9.

12. Costa R, Snipe R, Camões-Costa V, Scheer V, Murray A. The impact of gastrointestinal symptoms and dermatological injuries on nutritional intake and hydration status during ultramarathon events. Sports Med Open. 2016;2:16.

13. Malliaropoulos N, Mertyri D, Tsaklis P. Prevalence of injury in ultra trail running. Human Movement. 2015;16(2):52-9.

14. Hoffman MD, Stuempfle KJ. Muscle cramping during a 161-km ultramarathon: comparison of characteristics of those with and without cramping. Sports Med Open. 2015;1(1):24.

15. Schwabe K, Schwellnus M, Swanevelder S, Jordaan E, Derman W, Bosch A. Leisure athletes at risk of medical complications: outcomes of pre-participation screening among 15,778 endurance runners - SAFER VII. Phys Sportsmed. 2018;46(4):405-13.

16. Ranger TA, Wong AMY, Cook JL, Gaida JE. Is there an association between tendinopathy and diabetes mellitus? A systematic review with meta-analysis. $\mathrm{Br} J$ Sports $\mathrm{Med}$. 2016;50(16):982-9.

17. Abboud JA, Kim JS. The effect of hypercholesterolemia on rotator cuff disease. Clin Orthop Relat Res. 2010;468(6):1493-7.

18. Aicale R, Tarantino D, Maffulli N. Overuse injuries in sport: a comprehensive overview. J Orthop Surg Res. 2018;13(1):309.

19. Hattiholi J, Gaude GS. Prevalence and correlates of osteoporosis in chronic obstructive pulmonary disease patients in India. Lung India. 2014;31(3):221-7.

20. Nayyar N, Sood RG, Sarkar M, Tomar A, Thakur V, Bhoil R. Prevalence of osteoporosis and osteopenia in stable patients of chronic obstructive pulmonary disease in Sub-Himalayan region of Himachal Pradesh, India. J Family Med Prim Care. 2017;6(3):595-9.

21. Blanco I, Krähenbühl S, Schlienger RG. Corticosteroidassociated tendinopathies: an analysis of the published 
literature and spontaneous pharmacovigilance data. Drug Saf. 2005;28(7):633-43.

22. Hayem G. Statins and muscles: what price glory? Joint Bone Spine. 2002;69(3):249-51.

23. Kirchgesner T, Larbi A, Omoumi P, Malghem J, Zamali N, Manelfe J, et al. Drug-induced tendinopathy: from physiology to clinical applications. Joint Bone Spine. 2014;81(6):485-92.

24. Mandell L, Tillotson G. Safety of fluoroquinolones: an update. Can J Infect Dis. 2002;13(1):54-61.

25. Marie I, Noblet C. [Drug-associated tendon disorders: after fluoroquinolones... here are statins!]. Rev Med Interne. 2009;30(4):307-10.

26. Rice JB, White AG, Scarpati LM, Wan G, Nelson WW. Long-term systemic corticosteroid exposure: a systematic literature review. Clin Ther. 2017;39(11):2216-29.

27. Vuillemin V, Guerini H, Bard H, Morvan G. Stenosing tenosynovitis. J Ultrasound. 2012;15(1):20-8.

28. Hoffman M, Pasternak A, Rogers I, Khodaee M, Hill J, Townes D, et al. Medical services at ultra-endurance foot races in remote environments: medical issues and consensus guidelines. Sports Med. 2014;44(8):1055-69.

29. Laskowski-Jones L, Caudell MJ, Hawkins SC, Jones LJ, Dymond CA, Cushing T, et al. Extreme event medicine: considerations for the organisation of out-of-hospital care during obstacle, adventure and endurance competitions. Emerg Med J. 2017;34(10):680-5.

30. Dallinga J, Van Rijn R, Stubbe J, Deutekom M. Injury incidence and risk factors: a cohort study of $7068-\mathrm{km}$ or 16-km recreational runners. BMJ Open Sport Exerc Med. 2019;5(1):e000489.

31. van der Worp MP, de Wijer A, van Cingel R, Verbeek ALM. Nijhuis-van der Sanden MWG, Staal JB. The 5- or 10-km Marikenloop run: a prospective study of the etiology of running-related injuries in women. J Orthop Sports Phys Ther. 2016;46(6):462-70.

32. Borjesson M, Serratosa L, Carre F, Corrado D, Drezner J, Dugmore DL, et al. Consensus document regarding cardiovascular safety at sports arenas: position stand from the European association of cardiovascular prevention and rehabilitation (EACPR), section of Sports Cardiology. Eur Heart J. 2011;32(17):2119-24.

33. Schwellnus M, Swanevelder S, Derman W, Borjesson M, Schwabe K, Jordaan E. Prerace medical screening and education reduce medical encounters in distance road races: SAFER VIII study in 153208 race starters. Br J Sports Med. 2019;53(10):634-9.

34. Nielsen RO, Simonsen NS, Casals M, Stamatakis E, Mansournia MA. Methods matter and the "too much, too soon" theory (part 2): what is the goal of your sports injury research? Are you describing, predicting or drawing a causal inference? $\mathrm{Br} J$ Sports Med. 2020;54(22):1307-9.

35. Taunton JE, Ryan MB, Clement DB, McKenzie DC, LloydSmith DR, Zumbo BD. A prospective study of running injuries: the Vancouver Sun run "in training" clinics. $\mathrm{Br} J$ Sports Med. 2003;37(3):239-44.

36. Ward NC, Watts GF, Eckel RH. Statin toxicity. Circ Res. 2019;124(2):328-50.

37. Bolon B. Mini-review: toxic tendinopathy. Toxicol Pathol. 2017;45(7):834-7.

38. Robson-Ansley P, Howatson G, Tallent J, Mitcheson K, Walshe I, Toms C, et al. Prevalence of allergy and upper respiratory tract symptoms in runners of the London marathon. Med Sci Sports Exerc. 2012;44(6):999-1004.

39. Randall KL, Hawkins CA. Antihistamines and allergy. Aust Prescr. 2018;41(2):41-5.

40. Verschueren J, Tassignon B, De Pauw K, Proost M, Teugels A, Van Cutsem J, et al. Does acute fatigue negatively affect intrinsic risk factors of the lower extremity injury risk profile? A systematic and critical review. Sports Med. 2020;50(4):767-84.

41. Hespanhol Junior LC, van Mechelen W, Verhagen E. Health and economic burden of running-related injuries in Dutch trailrunners: a prospective cohort study. Sports Med. 2017;47(2):367-77.

42. Park S-K, Jeon H-M, Lam W-K, Stefanyshyn D, Ryu J. The effects of downhill slope on kinematics and kinetics of the lower extremity joints during running. Gait Posture. 2019;68:181-6. 